\title{
Fruit orchards under climate change conditions: adaptation strategies and management
}

\begin{abstract}
Under global warming and climate change conditions fruit orchards facing different environmental challenges which cause negative impacts on the growth and productivity of various fruit trees particularly in arid and semi-arid areas, various abiotic stress such as rising temperature, drought, heatwaves, and soil salinity represented a major challenge for growth and productivity of fruit orchards. Fruit trees used different strategies to cope with abiotic stress and minimize their adverse effects. Plants used different physiological, anatomical, and morphological mechanisms to tolerate abiotic stress, such as ion homeostasis, synthesis of more compatible solute, polyamines production, antioxidant regulation, closing stomata, in addition tol modification of root system, abscission of the leaves partially, compactness canopy, reducing leaf size, furthermore, under abiotic stress plants produce various organic solutes to cope with Reactive Oxygen solutes like Proline, in addition, using proper management practices that include providing adequate nutrients requirement particularly Potassium and Calcium, maintain soil moisture, using proper rootstocks tolerant for drought and salinity stress as well as exogenous application of plant growth substances could sustain orchards growth and productivity.
\end{abstract}

Keywords: abiotic stress, climate change, fruit orchards, physiological mechanism
Volume 8 Issue 3 - 202I

\author{
Waleed Fouad Abobatta \\ Horticulture Research Institute- Agriculture Research Center, \\ Egypt
}

Correspondence: Waleed Fouad Abobatta, Horticulture Research Institute- Agriculture Research Center- Giza- Egypt, Email wabobatta@yahoo.com

Received: May 10, 2021 | Published: June 30, 2021

\section{Introduction}

Environmental stresses are considered as major limitations threatening worldwide food security and have negative impacts on global crop production, there are various challenges facing fruit production particularly abiotic stresses that include rising temperature, reduction in precipitation, heatwaves, cold temperature, etc., which cause fluctuation in timing of flowering, fruit set, and harvesting date, adverse effects on productivity and fruit quality particularly in arid and semi-arid areas. ${ }^{1}$ Change in environmental elements like rising temperature, drought, freezing, heatwaves, elevation $\mathrm{CO}_{2}$ levels, and relative humidity, affect sustain production of various fruit orchards in both terms directly and indirectly, for instance, Citrus spp. one of the prominent fruit trees that need warm conditions for quality production, so, due to Change in climate factors like warm night during December and January in the northern hemisphere reduces flowering of citrus and increase vegetative growth which reflecting in decrease productivity and affect negatively fruit quality, ${ }^{2}$ furthermore, in Mango orchards (Mangifera Indica) heatwaves before and during flowering reduce flowering and increase fruit. ${ }^{3}$ Concurrent with the elevation of ambient temperatures, increases in evaporation, and reductions in precipitation rates, consequently, increase soil salinity. All these factors have negatively affect fruit orchards' growth, productivity, and fruit quality, particularly in the arid and semi-arid regions. Fruit orchards use various mechanisms to adapt to abiotic stresses based on different responses such as Morphological Adaptations, physiological Adaptations, and anatomy Adaptations, which in turn, lead to changes in plant metabolism to minimize stress-induced damage, ${ }^{4}$ furthermore, in order to face combinations of various stresses like drought and heat stress, plants specifically alter gene expression in a very different way than changes occurring in plants grown under single stress, in addition, modify management practices during growth seasons could enhance tree tolerance for various abiotic stresses. ${ }^{5,6}$
This work aims to discuss the main abiotic factors that affect fruit orchards' productivity and strategies used to adapt to stress conditions to improve growth and sustain the productivity of fruit orchards.

\section{Climate change factors}

\section{Drought}

Plants are very vulnerable when it comes to water scarcity, drought influences plant growth, development, productivity, and survival. However, the plants have used some protection strategies to adapt to drought conditions that include metabolic and morphological changes that prevent plants from dehydration injury. ${ }^{?}$

\section{Rising temperature}

Due to global warming, the global mean land and ocean surface temperatures have increased by $0.8 \mathrm{C}$ during the period 1888 to 2012 , also, the worldwide average surface temperature is foreseen to increase by 1.4 to $5.8 \mathrm{c}^{\circ}$ by 2100 , furthermore, rising temperature and heat waves have been mentioned from the 1950s of the last century, also, there is expected rising temperature will continue in the future, ${ }^{8}$ the elevated temperature has been described to cause faster crop development and thus to reduce crop duration, which is mainly associated with lower yields of various crops, while there are various impacts of higher temperature such as it could negatively affect photosynthetic carbon fixation and redistribution, as well as the electron transport chain occurring in the chloroplasts. ${ }^{9}$

\section{Salinity}

Salinity stress is a worldwide dilemma, and due to climate change, there is increasing in soil salinity which affected a wide range of arable land and various plants particularly fruit crops. Soil salinity, being one of the most detrimental abiotic stresses, critically damages crop plants 
and causes a significant reduction in the yield of various fruit crops, salinity tolerance is very complicated. ${ }^{10}$ Most fruit crops are sensitive to salinity stress and rarely fruit crops could tolerate higher salinity conditions, while, some crops like olive (Olea europaea) trees and date palm (Phoenix dactylifera $\mathrm{L}$.) could be grown under moderate salinity conditions. ${ }^{11}$

\section{Heatwaves}

Due to global warming, there are projected to occur intensive and longer heatwaves, fruit orchards are very sensitive to heatwaves particularly during flowering and fruit set stage, it could cause severe reduction in tree yield particularly when combined with drought stress. $^{12}$

\section{Adaptation strategies}

Abiotic stresses that include high temperature, drought, heatwaves, rising $\mathrm{CO}_{2}$ levels, and high salinity in soil and water, were known to affect metabolic processes such as photosynthesis and protein synthesis, resulting in decreased growth rate and reduction in yield with lower fruit quality, therefore, plants use various mechanisms under environmental stress conditions such as morphological, physiological, biochemical, and molecular transitions in gene expression to avoid adverse effects of stress. ${ }^{10}$

Impacts of the interactions between abiotic stress factors have a more adverse effect on fruit crops more than single stress. During signal transduction, the primary signal activates the production of secondary signaling molecules such as inositol phosphate and reactive oxygen species (ROS) resulting in the receptor-mediated release of $\mathrm{Ca}^{2+}$ in the cells. Drought stresses accompanied by salinity are the major climate threats that inhibit plants to exhibit their highest genetic potentials. ${ }^{13}$ There are different adaptation mechanisms used to enhance the growth and yield of various plants to overcome the adverse effect of abiotic stress on plant growth and sustain the productivity of fruit orchards. ${ }^{14}$

\section{Morphological adaptations}

Trees adapt to drought stress in various ways, like the evolutionary modification of root systems, canopy architecture, reducing leaf size, partially shedding leaves, dropping new fruit sets and small fruitlet, or other specific habits. ${ }^{15}$

\section{Modification of root system}

The growth of lateral roots is significantly reduced, mainly by suppression of activation of lateral root meristems, in addition to lateral roots, the presence of small roots is also an adaptive strategy to increase water absorption by providing a more absorbent surface, ${ }^{16}$ for instance, Arabian coffee plants (Coffea arabica L.) when facing drought for long period reducing the leaf area and minimizing produce new shoots for survival under stress conditions. ${ }^{17}$

\section{Deep root system}

The depth of root one of the mechanisms used to adapt to drought conditions, furthermore, trees with deep root systems like the Robusta coffee have a better tolerant ability to drought conditions. ${ }^{18}$ In addition fruit tree depends on secondary traits like root architecture, osmotic adjustment, leaf water potential, relative water content at the vegetative stage to enhance yield under drought stress. ${ }^{19}$

\section{Abscission of leaves}

Many crops had to shed the leaves partially when facing a water deficit for a long time, regularly shedding of older leaves start first to reduce water loss, then followed by young leaves when drought remain for a longer period..$^{20,21}$

\section{Canopy architecture}

Canopy architecture plays a significant role in adapting trees to stress conditions, so, Dwarf cultivars with dense crowns are more tolerant to drought as a result of reducing dehydration compare to wide-crown varieties. ${ }^{21}$ Compactness canopy reducing leaf size, also, change crown shape which reduces transpiration and saves energy by prevents high light density from reaching the inner leaves and decrease the penetration of the solar radiation to improve the microclimate in the tree, therefore, Dwarf cultivars with compacting crowns could tolerant drought more than open crown varieties by delaying dehydration.

\section{Anatomical adaptations}

Under environmental stress trees used anatomical adaptations to tolerate stress by reducing water loss by closing stomata which considered the main indicators under drought to reduce activity of photosynthetic enzymes such as ribulose-1,5-bisphosphate carboxylase/oxygenase [Rubisco], ${ }^{23}$ also, under drought stress plant minimize the number of stomata to adapt with water shortage conditions.

\section{Physiologically adaptations}

Under abiotic stress like drought and soil salinity plants produce different organic solutes through activated gluconeogenesis and photorespiration to cope with Reactive Oxygen solutes (ROS) and photoinhibition, by increasing glucose, malate, and proline levels to adjust osmotically. Generally, plants adapt to drought through different ways like drought escape, tolerance, and avoidance strategies, which have no clear-cut boundaries..$^{24}$ for instance, under drought and hightemperature conditions citrus trees, particularly those grafting on Cleopatra rootstock activate biosynthesis of flavonoids to mitigate the higher oxidative damage.

Biosynthesis of Jasmonic acid (JA) one of the physiological mechanisms used to adapt to stress conditions, plant synthesis of JA by different types of plastids, cytoplasmic enzymes, and peroxisomes. JA has a positive effect on salt tolerance, it acts as a regulator for plant development under salinity stress, so, using JAs as a foliar application increasing tolerance of fruit trees for salinity stress and enhancing vigor, and improves productivity. ${ }^{25}$

\section{Role of potassium in plant cell}

Potassium $(\mathrm{K}+)$ plays as a charge balancing ion in plant cells and Cytosolic, also, Potassium $(\mathrm{K}+)$ homeostasis is very critical in terms of stress tolerance in plants, ${ }^{26}$ Potassium retention in mesophyll cells is a major strategy for the existence of salt tolerance, while, plants show various $(\mathrm{K}+)$ retention abilities. ${ }^{27}$

Stress conditions cause a disturbance in $\mathrm{K}+$ balance in the plant cells, which lose $\mathrm{K}+$ under soil salinity stress due to two main factor affect $\mathrm{K}+$ balance in plant cell

1. The activation of caspase-like proteases and endonucleases,

2. Inevitable influx of Sodium $(\mathrm{Na}+)$ induces an abrupt membrane depolarization, which affects the transport of major essential elements across the plasma membrane.

Therefore, under soil salinity conditions fertilizing with adequate Potassium reduces adverse effects on the plant. ${ }^{28}$ 


\section{Management practices}

There are different steps required to maintain orchards productivity under climate change conditions and abiotic stresses, therefore, using proper agricultural practice with adequate nutrients requirement and maintain soil moisture, with tolerant rootstocks for drought or/and salinity stress, in addition to exogenous application of plant growth regulators, could play a significant role in the sustained production of fruit orchards under harsh climate conditions. ${ }^{29}$

Some application used to improve orchards productivity under abiotic stress:

a. Using organic solutes like Jasmonic acid, Salicylic acid, and Proline to increase tree tolerance for various abiotic stress. ${ }^{30}$

b. Foliar application of Alcoholic sugar like Sorbitol, and Mannitol. ${ }^{31}$

c. Regular application of humate compounds to reduce soil salinity.

d. Use proper fertilizers type for physiological stage

e. Use the proper quantity of Potassium and Calcium fertilizers during growth season.

f. Microelements are essential for improving tree growth.

g. Growth regulators such as Gibberellic acid and Cytokinin play important role in plant metabolism. ${ }^{32}$

\section{Conclusion}

Due to various challenges that facing fruit orchards particularly abiotic stress like drought, rising temperature, heatwaves, and soil salinity, which affect negatively vegetative growth and productivity. Fruit trees use various physiological, anatomical, and morphological strategies to cope with the adverse effects of stressful conditions, produce more compatible solute, polyamines synthesis, closing stomata, in addition to modification of root system and deep root system, abscission of the leaves partially, compactness canopy, reducing leaf size, considered important mechanisms to cope with abiotic stresses without loss of yield or productivity, in addition, using appropriate agricultural practices maintain soil moisture, using proper rootstocks tolerant for stress as well as exogenous application of plant growth substances could sustain orchards growth and productivity.

\section{Acknowledgments}

None.

\section{Conflicts of interest}

The author declares that there is no conflict of interest.

\section{Funding}

None.

\section{References}

1. Mattos LM, Moretti CL, Jan S, et al. Climate changes and potential impacts on quality of fruit and vegetable crops. In Emerging technologies and management of crop stress tolerance. 2014. p. 467-486.

2. Shafqat W, Naqvi SA, Maqbool R, et al. Climate Change and Citrus. In Citrus. IntechOpen. 2021.
3. Rao NS, Laxman RH, Shivashankara, KS. Physiological and morphological responses of horticultural crops to abiotic stresses. In Abiotic stress physiology of horticultural crops Springer, New Delhi? 2016. p. 3-17.

4. Hutton RJ, Loveys BR. A partial root zone drying irrigation strategy for citrus - effects on water use efficiency and fruit characteristics. Agricultural Water Management. 2011;98(10):1485-1496.

5. Kijowska-Oberc J, Staszak AM, Kamiński J, et al. Adaptation of forest trees to rapidly changing climate. Forests. 2020;11(2):123.

6. Keller M. Managing grapevines to optimise fruit development in a challenging environment:a climate change primer for viticulturists. Australian Journal of Grape and Wine Research. 2010;16:56-69.

7. Zia R, Nawaz MS, Siddique MJ, et al. Plant survival under drought stress:Implications, adaptive responses, and integrated rhizosphere management strategy for stress mitigation. Microbiological Research. $2020 ; 126626$.

8. Perkins-Kirkpatrick SE, Lewis SC. Increasing trends in regional heatwaves. Nature communications. 2020;11(1):1-8.

9. Hatfield JL, Prueger JH. Temperature extremes: Effect on plant growth and development. Weather and climate extremes. 2015;10:4-10.

10. Abobatta WF. Plant Responses and Tolerance to Combined Salt and Drought Stress. In Salt and Drought Stress Tolerance in Plants. 2020. p. $17-52$.

11. Fernández-Escobar R. Olive nutritional status and tolerance to biotic and abiotic stresses. Frontiers in plant science. 2019;10:1151.

12. Parker LE, McElrone AJ, Ostoja SM, et al. Extreme heat effects on perennial crops and strategies for sustaining future production. Plant Science. 2020;295:110397.

13. Xiong L, Schumaker KS, Zhu JK. Cell signaling during cold, drought, and salt stress. The plant cell. 2002;14(1):S165-S183.

14. Vinod KK. Stress in plantation crops:adaptation and management. In Crop Stress and its Management:Perspectives and Strategies. 2012. p. 45-137.

15. Connor DJ, Fereres E. The physiology of adaptation and yield expression in olive. Horticultural reviews. 2005;31:155-229.

16. Seo PJ, Park CM. Auxin homeostasis during lateral root development under drought condition. Plant signaling \& behavior. 2009;4(10):10021004 .

17. DaMatta FM, Avila RT, Cardoso AA, et al. Coffee tree growth and environmental acclimation. Achieving Sustainable Cultivation of Coffee. Breeding and Quality Traits. 2018.

18. Pinheiro HM, Touraud E, Thomas O. Aromatic amines from azo dye reduction:status review with emphasis on direct UV spectrophotometric detection in textile industry wastewaters. Dyes and pigment. 2004;61(2):121-139.

19. Tardieu F, Simonneau T, Muller B. The physiological basis of drought tolerance in crop plants:a scenario-dependent probabilistic approach. Annual review of plant biology. 2018;69:733-759.

20. DaMatta FM, Rena AB. Effects of fruiting on the growth of Arabica coffee trees as related to carbohydrate and nitrogen status and to nitrate reductase activity. Revista Brasileira de Fisiologia Vegetal. 2001;13(1):66-74.

21. López R, Cano FJ, Martin-StPaul NK, et al. Coordination of stem and leaf traits define different strategies to regulate water loss and tolerance ranges to aridity. New Phytologist. 2021;230(2):497-509.

22. Iqbal A, Fahad S, Iqbal M, et al. Special Adaptive Features of Plant Species in Response to Drought. In Salt and Drought Stress Tolerance in Plants. 2020. p. 77-118. 
23. Feng BH, Li GY, Islam M, et al. Strengthened antioxidant capacity improves photosynthesis by regulating stomatal aperture and ribulose-1, 5-bisphosphate carboxylase/oxygenase activity. Plant Sci. 2020;290:110245.

24. Hassan MU, Chattha MU, Khan I, et al. Heat stress in cultivated plants:nature, impact, mechanisms, and mitigation strategies-a review. Plant Biosystems-An International Journal Dealing with all Aspects of Plant Biology. 2020;1-24.

25. Ali M, Baek KH. Jasmonic acid signaling pathway in response to abiotic stresses in plants. International journal of molecular sciences. 2020;21(2):621

26. Wang M, Zheng Q, Shen Q, et al. The critical role of potassium in plant stress response. International journal of molecular sciences. 2013;14(4):7370-7390.

27. Wu H, Zhu M, Shabala L, et al. $\mathrm{K}+$ retention in leaf mesophyll, an overlooked component of salinity tolerance mechanism: a case study for barley. Journal of integrative plant biology. 2015;57(2):171-185.
28. Shabala S, Pottosin I. Regulation of potassium transport in plants under hostile conditions:implications for abiotic and biotic stress tolerance. Physiologia plantarum. 2014;151(3):257-279.

29. Abobatta WF. Managing citrus orchards under climate change. MOJ Eco Environ Sci. 2021;6(2):43-44.

30. Khan MIR, Fatma M, Per TS, et al. Salicylic acid-induced abiotic stress tolerance and underlying mechanisms in plants. Frontiers in plant science. 2015;6:462.

31. Nosarzewski M, Downie AB, Wu B, et al. The role of sorbitol dehydrogenase in Arabidopsis thaliana. Functional Plant Biology. 2012;39(6), 462-470.

32. Javid MG, Sorooshzadeh A, Moradi F, et al. The role of phytohormones in alleviating salt stress in crop plants. Australian Journal of Crop Science. 2011;5(6):726-734. 